\title{
QUAL O CONCEITO DE DOCÊNCIA? ENTRE RESISTÊNCIAS E INVESTIGAÇÕES
}

Qual el concepto de enseñanza? Entre resistencia e investigación

Wich is teaching concept? Between resistance and research

Nilson de Souza Cardoso*

Isabel Maria Sabino de Farias**

https://doi.org/10.38117/2675-181X.formov2020.v2i2n4.395-415

\section{RESUMO}

O texto apresenta análise acerca do "conceito de docência" no campo da formação de professores, considerando produções acadêmicas (teses, dissertações e artigos) publicados entre 2015 e 2019. Ancora-se em "evidências da leitura" a partir da sistematização de levantamento bibliográfico do tipo Estado da Questão, composto por 07 artigos, 08 dissertações e 08 teses disponíveis em bancos de dados online. $\mathrm{O}$ conceito de docência é um construto basilar para a compreensão dos elementos que podem evidenciar uma conceituação alargada de docência. Relaciona a docência como atividade intencional, subjetiva e complexa, com apenas dois trabalhos apresentando alguma referência à dimensão política da ação docente, elemento fundante do conceito de docência ampliada. A temática recebeu atenção tímida nas produções acadêmicas dos últimos cinco anos, ao mesmo tempo em que desvelam a componente da consciência como importante para compreensão do conceito de docência numa perspectiva ampliada.

PALAVRAS CHAVE: Concepção de docência; Dimensão política; Formação de professores.

\section{RESUMEN}

El texto presenta un análisis sobre el "concepto de enseñanza" en el campo de la formación docente, considerando las producciones académicas (tesis, disertaciones y artículos) publicados entre 2015 y 2019. Está anclado en "evidencias de lectura" basadas en la encuesta bibliográfica sistemática del tipo de Estado de la pregunta, compuesto por 07 artículos, 08 disertaciones y 08 tesis disponibles en bases de datos en línea. El concepto de enseñanza es una construcción básica para comprender los 
elementos que pueden evidenciar un concepto amplio de enseñanza. Relaciona la enseñanza como una actividad intencional, subjetiva y compleja, con solo dos trabajos que presentan alguna referencia a la dimensión política de la acción docente, un elemento fundador del concepto de enseñanza expandida. El tema recibió una atención tímida en las producciones académicas de los últimos cinco años, al mismo tiempo que revelaron el componente de la conciencia como importante para comprender el concepto de enseñanza en una perspectiva ampliada.

PALABRAS CLAVE: Concepción docente; Dimensión política; Formación del professorado.

\begin{abstract}
The text presents an analysis of the "concept of teaching" in the field of teacher education, considering academic productions (theses, dissertations and articles) published between 2015 and 2019. It is anchored in "evidence of reading" based on the systematic bibliographic survey type State of the Question, consisting of 07 articles, 08 dissertations and 8 theses available in online databases. The concept of teaching is a basic construct for understanding the elements that can evidence a broad concept of teaching. It relates teaching as an intentional, subjective and complex activity, except for two works make any reference to the political dimension of the teaching action, a founding element of the concept of expanded teaching. The issue attracted minor interest in academic productions in the last five years, at the same time that reveals the concept of expanded teaching awareness as an important element for understanding the concept of teaching as a broad perspective.
\end{abstract}

KEYWORDS: Conception of teaching; Political dimension; Teacher education.

\title{
Introdução
}

A análise aqui proposta busca compreender, considerando produções acadêmicas, a temática "conceito de docência" no campo da formação de professores. Este interesse advém das práticas formativas vivenciadas, sobretudo na última década, no âmbito de iniciativas envolvendo professores formadores ligados a docência na Educação Superior, em particular a participação no Programa Institucional de Bolsa de Iniciação a Docência - Pibid, bem como no movimento social em sua defesa.

Parte-se da percepção de que o envolvimento nessa iniciativa deu aos(às) professores(as) alargamento do que é ser um(a)formador(a), do que é a docência, para 
além das questões estritamente relacionadas ao ensinar e ao aprender em áreas/disciplinas/componentes curriculares. Tal alargamento perpassa pela assunção da dimensão política nos modos de compreender e atuar como docente responsável pela formação de outras(os) docentes. Esse é o cerne de um estudo em desenvolvimento em nível de doutoramento em educação e que se dedica a compreender a relação que o(a) professor(a) formador(a) tem com essa dimensão de sua atuação profissional, ou seja, de se perceber, de investir e de incorporar seu papel como sujeito político. O conceito de docência apresenta-se, assim, como um construto basilar ao desvelamento dessa questão, empreitada cujos primeiros indicativos abordamos nesse escrito.

Problematiza-se, a princípio, como se delineia o conceito de docência, ponderando-se, então, sobre como o cenário atual nos convoca a lançar olhares para o docente como sujeito político. Na sequência, explicita-se o percurso e delimita-se o corpus de análise do exame bibliográfico realizado, configurado aqui no formato de um Estado da Questão, indicando o marco temporal e as fontes utilizadas nessa investigação, precisamente artigos, teses e dissertações. As análises, as discussões e as considerações sobre os achados em torno do conceito de docência compõem o desfecho desse artigo.

\section{Docência e Política Educacional - dos ataques às resistências}

As diversas temáticas ligadas à Educação têm figurado nos noticiários de maneira surpreendente, dada a retomada de medidas e adoção de concepções consideradas já ultrapassadas, mas que ganham novos tons, sons e grafias, notadamente após o golpe de 2016 e a eleição do Governo Bolsonaro.

De certo que os ataques não estão circundados apenas à Educação, outros direitos sociais têm sofrido com a investida privada, a exemplo da previdência social. Por outro lado, o setor da Educação é o que tem conseguido mobilizar no sentido de fazer alguns enfrentamentos, organizando-se em atos e coletivos que buscam resistir, a exemplo da paralização de 15 de maio de 2019 (15M), reunindo em todo o país milhares de pessoas "em defesa da educação pública" e "contra os cortes" nos orçamentos, sobretudo em pautas ligadas ao Ensino Superior Público.

Observa-se que além da pauta conservadora que circula em torno dos projetos denominados "Escola sem Partido", acentua-se o aprofundamento os ataques liberais na Educação, expressos na reforma do Ensino Médio (Lei n $\left.{ }^{0} 13.415 / 2017\right)$; na mudança na política de alfabetização brasileira (Decreto $n^{0} 9.765 / 2019$ ), que se pauta na literacia e numeracia; na imposição de uma Base Nacional Comum Curricular para Educação Básica; e, mais recentemente, na publicação de novas diretrizes para formação de professores(as) e de uma Base Nacional da Formação (Resolução no 02/2019 - CP/CNE), processos marcados pelo retorno das competências e habilidades como único caminho 
curricular. Medidas que distanciam a implantação de um Sistema Nacional de Educação, como preconiza o PNE (Lei $n^{\circ} 13.005 / 2014$ ), desmonte que, pelas características dos governantes atuais, tem passado ao largo de processo democráticas, alijando professoras(es), gestoras(es) e pesquisadoras(es) das discussões dessas questões, requerendo, mais do que a qualquer tempo, envolvimento político para defesas e resistências às desconfigurações ante o avanço dos interesses econômicos e/ou ideológicos na Educação, em especial a educação pública.

Nesses contextos de desmontes, registra-se, desde 2015, o desmantelamento de ações de fortalecimento da formação inicial desenvolvidas no âmbito da Coordenação de Aperfeiçoamento de Pessoal de Nível Superior (CAPES), tendo resistido basicamente o Pibid. Destaca-se na permanência deste Programa a atuação do Fórum de Coordenadores Institucionais do Pibid (Forpibid), cuja organização de origem popular, articulado à sociedade civil, a entidades educacionais e aos diversos níveis de parlamento pelo País, fez diversos enfrentamentos e obteve êxito (VILLAS-BÔAS, 2018).

A expressão do movimento em defesa do Pibid, a hashtag \#ficapibid, ganhou rápida projeção nacional e marcou o envolvimento de diversos atores no cenário educacional, não limitados à docentes e estudantes vinculados aos programas, mas entidades, gestores escolares, pais e demais membros das comunidades acadêmicas e escolares envolveram-se em iniciativas promovidas pelo Forpibid-rp a partir de 2015, quando ocorreu o primeiro indício de interrupção do Programa. Nestes contextos de mobilizações ocorreram audiências públicas no Congresso Nacional e em diversas casas legislativas em municípios e estados do Brasil, reuniram mais 500 mil assinaturas em um conjunto de abaixo-assinados e, com o apoio parlamentar, lançaram um projeto de lei e uma frente parlamentar cujo intento era tornar o Pibid uma política de Estado, porém sem o efetivo sucesso. Após enfrentar tentativa do Pibid, o Fórum compõe com os coordenadores de um novo programa de apoio e valorização da formação inicial, o Residência Pedagógica e passa a identificar-se como Fórum de Coordenadores Institucionais do Pibid e Residência Pedagógica (Forpibid-rp) (CARDOSO; MENDOÇA, 2019).

Parte-se da compreensão de que os sujeitos que participaram desses momentos, deflagrando processos e experiências em dimensões pouco exploradas no campo da formação, a exemplo da política, quando tiveram oportunidade e protagonismo nos enfrentamentos aos intentos do Governo Federal, vivenciaram uma experiência formadora (JOSSO, 2004). Este pressuposto nos leva a questionar se a participação nessas ações de resistência fomentou a consciência política desses sujeitos, se o envolvimento na luta pela permanência das vicissitudes observadas no Pibid implicou nova atuação do(a) professor(a) formador(a). 
Essas inquietações encontram-se no centro do interesse em compreender como o conceito de docência figura na tematização nacional, para, com bases nos aportes desse exame, tecer considerações que possam evidenciar indicativos de desenvolvimento de uma perspectiva alargada de docência decorrente da assunção da dimensão política nos modos de compreender e atuar como docente.

Como percurso metodológico, esta análise buscou suporte no levantamento bibliográfico configurado no formato de um Estado da Questão (EQ), tal como formulado por Nóbrega-Therrien e Therrien (2011). Esses autores brasileiros compreendem o EQ como caminho para demarcar e especificar o objeto de estudo, permitindo dar-lhe "especificidade" para "posteriormente, à elaboração das categorias de análises necessárias para a interpretação dos dados, constituindo, assim, a fundamentação teórica do estudo" (NÓBREGA-THERRIEN; THERRIEN, 2011, p. 34). Adicionalmente, o EQ permite avaliar como "se encontra o tema ou o objeto de sua investigação no estado atual da ciência ao seu alcance", acrescentam os referidos autores (NÓBREGA-THERRIEN; THERRIEN, 2004, p. 07).

O levantamento bibliográfico desenvolvido apoiou-se, portanto, no reconhecimento de que esse procedimento focaliza evidências da leitura (BELL, 2008) ${ }^{1}$ com o objetivo de ampliar para enxergar o problema de pesquisa, tal como propõe Stake (2011).A seguir, a imersão nesse universo será descrita pelos achados em produções acadêmicas qualificadas, a saber: artigos em periódicos indexados, teses e dissertações publicadas nos últimos cinco anos.

\section{Conceito de docência: levantamento e análise das produções acadêmicas no cenário nacional, no último quinquênio (2015-2019).}

Para este estudo, temporalmente, o olhar foi lançado sob teses, dissertações e artigos publicados entre 2015 e 2019, último quinquênio, o qual também compreende o período em que se discutiu a reformulação curricular da formação de professores(as). As diretrizes aprovadas em 2015 explicitam um conceito de docência, cuja formulação deveria nortear as práticas formativas. Nos termos da Resolução do CNE/CP n ${ }^{\circ}$ 02/2015, o conceito de docência se sobressai:

[...] como ação educativa e como processo pedagógico intencional e metódico, envolvendo conhecimentos específicos, interdisciplinares e pedagógicos, conceitos, princípios e objetivos da formação que se desenvolvem entre conhecimentos científicos e culturais, nos valores éticos, políticos e estéticos inerentes ao ensinar e aprender, na

\footnotetext{
${ }^{1}$ Conforme a pesquisadora britânica Judith Bell (2008, p. 97), a “evidência da leitura" é necessária em toda pesquisa e sua relevância centra-se, justamente, na produção de uma lente teórica sobre o objeto de estudo.
} 
socialização e construção de conhecimentos, no diálogo constante entre diferentes visões de mundo [...] (BRASIL, 2015).

Foi considerando as orientações advindas desse debate que o marco temporal de referência do presente levantamento bibliográfico foi definido. Elegeu-se como fontes bibliográficas para fomentar a elaboração EQ, aquelas disponíveis no portal de Periódicos CAPES, reconhecido como plataforma publica ampla, significativa e segura de produções acadêmicas, em especial, artigos indexados e avaliados por pares, e também na Biblioteca Digital Brasileira de Teses e Dissertações (BDTD), dada a sua capacidade repositória das produções acadêmicas em pós-graduação brasileira.

O levantamento realizado no Portal de Periódicos CAPES ${ }^{2}$, utilizando o descritor "conceito de docência" ou "concepção de docência" (compreendidos como sinônimos), com o advento das aspas e do boleano $O R$, em artigos avaliados por pares e publicados desde 2015, chega-se ao quantitativo de 8 artigos, disponíveis em periódicos em diversas áreas do conhecimento, todas dentro do campo de Ciências Humanas (ver Quadro 01).

Quadro 1 - Quantitativo de artigos presentes no portal Periódicos Capes, no período 2015 a 2019 e que possuíam os descritores "Conceito" ou "Concepção" de docência.

\begin{tabular}{|l|c|}
\hline Descritor 1 & Conceito de docência \\
\hline Sem refinamentos & 05 \\
\hline Refino período (2015/2019) & 03 \\
\hline Refino revisão por pares & 03 \\
\hline Dispensados após leitura resumo & 00 \\
\hline Descritor 2 & 14 \\
\hline Sem refinamentos & 09 \\
\hline Refino período (2015/2019) & 08 \\
\hline Refino revisão por pares & 03 \\
\hline Dispensados após leitura resumo ${ }^{3}$ & 18 \\
\hline Descritor 3 & Concepção de docência OR Conceito de Docência \\
\hline Sem refinamentos & 11 \\
\hline Refino período (2015/2019) & 10 \\
\hline Refino revisão por pares & 03 \\
\hline Dispensados após leitura resumo & 07 \\
\hline Total eleito para análise & \\
\hline
\end{tabular}

Fonte: Organizado pelos autores (2020).

\footnotetext{
${ }^{2}$ Portal acessado por meio do link: http://www-periodicos-capes-gov-br.ez76.periodicos.capes.gov.br/
} 
Destes, após leitura dos resumos, envereda-se pela análise de 07, pois um deles estava relacionado tanto à concepção de docência, quanto ao conceito de docência, conforme detalhado no Quadro 02.

Quadro 2 - Congruência dos descritores entre os artigos analisados

\begin{tabular}{|c|c|}
\hline \multicolumn{2}{|l|}{ Descritor 1: Conceito de Docência } \\
\hline Artigo & Autores \\
\hline $\begin{array}{l}\text { Aprendendo a ensinar na formação inicial de professores de } \\
\text { matemática: uma análise das concepcões discentes (1) }\end{array}$ & $\begin{array}{l}\text { Volkman, E.; Pereira, } \\
\text { A.; Luccas, S. }\end{array}$ \\
\hline $\begin{array}{l}\text { Metodologias Ativas na formação profissional em saúde: uma } \\
\text { revisão (2) }\end{array}$ & $\begin{array}{l}\text { Colares, K. T. } \\
\text { Oliveira, W. }\end{array}$ \\
\hline $\begin{array}{l}\text { O potencial formativo do Pibid pela perspectiva dos formadores de } \\
\text { professores (3) }\end{array}$ & $\begin{array}{l}\text { Massena, E. P.; Cunha, } \\
\text { M. I. }\end{array}$ \\
\hline \multicolumn{2}{|l|}{ Descritor 2: Concepção de Docência } \\
\hline Artigo & Autores \\
\hline $\begin{array}{l}\text { Aprendendo a ensinar na formação inicial de professores de } \\
\text { matemática: uma análise das concepções discentes (1) }\end{array}$ & $\begin{array}{l}\text { Volkman, E.; Pereira, } \\
\text { A.; Luccas, S. }\end{array}$ \\
\hline Formação docente no Brasil: Cenários e desafios (4) & Martins, L.; Battisti, A. \\
\hline $\begin{array}{l}\text { Formação continuada: a visão dos professores de um curso de } \\
\text { graduação tecnológica (5) }\end{array}$ & $\begin{array}{l}\text { Paez, F. M.; Pereira, A. } \\
\text { S. }\end{array}$ \\
\hline $\begin{array}{l}\text { Pós-graduação stricto sensu em Direito: onde e como se forma o } \\
\text { docente dos cursos de graduação (6) }\end{array}$ & $\begin{array}{l}\text { Prado, E. C.; Santos, C. } \\
\text { M.; Pereira, A. M., Jr. }\end{array}$ \\
\hline $\begin{array}{l}\text { Plano nacional de educação e seus desdobramentos sobre as novas } \\
\text { diretrizes para a formação de professores da educação profissional: } \\
\text { identidades profissionais em construção (7) }\end{array}$ & Silva, F. \\
\hline \multicolumn{2}{|c|}{ Descritor 3: Concepção de docência OR Conceito de Docência } \\
\hline Artigo & Autores \\
\hline $\begin{array}{l}\text { Aprendendo a ensinar na formação inicial de professores de } \\
\text { matemática: uma análise das concepções discentes (1) }\end{array}$ & $\begin{array}{l}\text { Volkman, E.; Pereira, } \\
\text { A.; Luccas, S. }\end{array}$ \\
\hline $\begin{array}{l}\text { Metodologias Ativas na formação profissional em saúde: uma } \\
\text { revisão (2) }\end{array}$ & $\begin{array}{lll}\text { Colares, K. } & \text { T. } & \text { P.; } \\
\text { Oliveira, W. } & \end{array}$ \\
\hline $\begin{array}{l}\text { O potencial formativo do Pibid pela perspectiva dos formadores de } \\
\text { professores (3) }\end{array}$ & $\begin{array}{l}\text { Massena, E. P.; Cunha, } \\
\text { M. I. }\end{array}$ \\
\hline Formação docente no Brasil: Cenários e desafios (4) & Martins, L.; Battisti, A. \\
\hline $\begin{array}{l}\text { Formação continuada: a visão dos professores de um curso de } \\
\text { graduação tecnológica (5) }\end{array}$ & $\begin{array}{l}\text { Paez, F. M.; Pereira, A. } \\
\text { S. }\end{array}$ \\
\hline $\begin{array}{l}\text { Pós-graduação stricto sensu em Direito: onde e como se forma o } \\
\text { docente dos cursos de graduação (6) }\end{array}$ & $\begin{array}{l}\text { Prado, E. C.; Santos, C. } \\
\text { M.; Pereira, A. M., Jr. }\end{array}$ \\
\hline $\begin{array}{l}\text { Plano Nacional de educação e seus desdobramentos sobre as novas } \\
\text { diretrizes para a formação de professores da educação profissional: } \\
\text { identidades profissionais em construção (7) }\end{array}$ & Silva, F. \\
\hline
\end{tabular}

Em meio aos artigos em periódicos indexados, elencados nos Quadros 01 e 02, observou-se diminuto investimento das pesquisas na conceituação sobre a docência, uma vez que a busca geral, sem delimitação de período de publicação, localizou apenas 18 artigos no Portal Periódicos CAPES, considerando os dois descritores utilizados. Quando aplicado o refinamento temporal, percebe-se que o interesse pela temática se concentra 
nos últimos 5 anos. Convém destacar que dois registros foram dispensados por tratar-se de entrevista, um outro artigo foi excluído pela observação do descritor constar apenas como título de uma referência utilizada, sem, contudo, problematizar sobre a questão proposta para esse estudo. Entre os 07 artigos escolhidos apenas um foi localizado pelos os dois descritores elencados.

Nas consultas na BDTD ${ }^{4}$ utilizou-se os mesmos descritores outrora definidos, exceto a junção nas buscas com o boleano "OR", dada a impossibilidade de aplicação na plataforma da referida biblioteca. Assim, após o refinamento de consulta, notadamente, as teses e dissertações publicadas nos últimos 5 anos, chegamos ao quantitativo de 06 documentos que possuem discussão sobre "Conceito de Docência" e 13 para os textos defendidos em pós-graduação que tratam da "Concepção de Docência” (ver Quadro 03).

Quadro 03 - quantitativo de dissertações e teses identificadas com os descritores "concepção de docência" e "conceito de docência" na BDTD - 2015 a 2019

\begin{tabular}{|l|c|}
\hline Descritor 1 & Conceito de docência \\
\hline Sem refinamentos & 16 \\
\hline Refino período (2015/2019) & 06 \\
\hline Não acessadas & 00 \\
\hline Analisadas & 06 \\
\hline Descritor 2 & 28 \\
\hline Sem refinamentos & 13 \\
\hline Refino período (2015/2019) & 03 \\
\hline Não acessadas 5 & 10 \\
\hline Analisadas & 16 \\
\hline Total eleito para análise & \\
\hline
\end{tabular}

Fonte: Organizado pelos autores (2020).

Embora não tenha sido registrada interposição entre os achados, 03 documentos não puderam ser socializados, sendo 02 por apresentar bloqueio temporal da própria instituição e outro por apresentar algum problema no link de acesso, efetivando-se a leitura de 16 teses ou dissertações que foram eleitas para análise (ver Quadro 04).

\footnotetext{
${ }^{4}$ Biblioteca acessada por meio do link: http://bdtd.ibict.br/vufind/

${ }^{5}$ Embora os resumos estivessem presentes nos resultados das buscas realizadas, o inteiro teor da tese/dissertação não estava disponível na BDTD.
} 
Quadro 04 - Teses e dissertações quem compõem o corpus de análise do EQ.

\begin{tabular}{|c|c|c|c|}
\hline Autor/Ano & $\begin{array}{c}\text { Curso- } \\
\text { Programa/IES }\end{array}$ & Tipo & Título \\
\hline ALMEIDA, 2015 & PPGE/UMSP & Dissertação & $\begin{array}{l}\text { O ensino da filosofia nas diretrizes de Jean } \\
\text { Maugüé e no Historicismo do pensamento de } \\
\text { João da Cruz Costa: o pioneirismo na } \\
\text { Universidade de São Paulo }\end{array}$ \\
\hline BRODBECK, 2015 & PPGE/UNISINOS & Tese & $\begin{array}{l}\text { Docência em ciências nas práticas pibidianas } \\
\text { do Subprojeto Biologia e a produção de uma } \\
\text { Pedagogia da Redenção }\end{array}$ \\
\hline GUARDIEIRO, 2015 & PPGE/UFG & Dissertação & $\begin{array}{l}\text { Docência e história de vida no curso técnico } \\
\text { em magistério de Gatalão-GO }\end{array}$ \\
\hline STORK, 2015 & PPGE/UFRG & Dissertação & $\begin{array}{l}\text { Como viver na escola: relações entre arte, } \\
\text { educação e docência }\end{array}$ \\
\hline SELBACH, 2016 & PPGE/UCS & Dissertação & $\begin{array}{l}\text { A constituição da docência em blogs do } \\
\text { PIBID: Um estudo sobre os modos de escrita } \\
\text { de si }\end{array}$ \\
\hline BEZERRA, 2017 & PPGE/UFPB & Dissertação & $\begin{array}{l}\text { A formação de professores no Brasil: um } \\
\text { estudo das diretrizes curriculares nacionais } \\
\text { para a formação inicial e continuada dos } \\
\text { professores }(2002-2015)\end{array}$ \\
\hline CORRÊA, 2017 & PPGE/UFJF & Tese & $\begin{array}{l}\text { A formação dos formadores do Programa } \\
\text { Institucional de Bolsa de Iniciação à } \\
\text { Docência (PIBID) }\end{array}$ \\
\hline SABBAG, 2017 & PPGE/UFSC & Tese & $\begin{array}{l}\text { "Porque a gente tem um corpo né... Mas a } \\
\text { gente só lembra do corpo quando ele dói!" A } \\
\text { centralidade do corpo adulto nas relações } \\
\text { educativas na Educação infantil }\end{array}$ \\
\hline SANDRI, 2017 & PPGE/UFSM & Tese & $\begin{array}{l}\text { Aprendizagem docente no ensino superior: } \\
\text { processos formativos de professores e } \\
\text { estudantes nas licenciaturas da área de } \\
\text { ciências biológicas, exatas e da terra }\end{array}$ \\
\hline SANTOS, 2017 & PPGQ/UFG & Tese & $\begin{array}{l}\text { A formação no curso de licenciatura em } \\
\text { química UFG/Goiânia: a relação entre a } \\
\text { formação e o trabalho docente }\end{array}$ \\
\hline MANZONI, 2018 & PPGE/UFSM & Tese & $\begin{array}{l}\text { Dançografia em processo de criação: uma } \\
\text { docência artista em dança }\end{array}$ \\
\hline OLIVEIRA, 2018 & PPGENF-PSI/USP & Tese & $\begin{array}{l}\text { Docência Universidade na Saúde: limites e } \\
\text { possibilidades para uma prática inovadora }\end{array}$ \\
\hline SILVA, 2018 & PPGE/UFMG & Tese & $\begin{array}{l}\text { Carência de professores licenciados em } \\
\text { matemática em Corrente: um estudo a partir } \\
\text { das representações sociais }\end{array}$ \\
\hline DI NÁPOLI, 2019 & PPGE/UFG & Dissertação & $\begin{array}{l}\text { A formação inicial de professores e a } \\
\text { educação de jovens e adultos }\end{array}$ \\
\hline RIBEIRO, 2019 & PPGE/UNIOESTE & Dissertação & $\begin{array}{l}\text { Formação pedagógica nos programas de pós- } \\
\text { graduação Stricto Sensu da Unioeste/ } \\
\text { Campus Cascavel-PR: um estudo sobre o } \\
\text { estágio de docência. }\end{array}$ \\
\hline
\end{tabular}




\begin{tabular}{|l|l|l|l|}
\hline RONCARELLI, 2019 & PPGE/UCS & Dissertação & $\begin{array}{l}\text { Docência em movimento, entrecruzamentos } \\
\text { de percursos de vida e percursos docentes: o } \\
\text { que acontece com as professoras? }\end{array}$ \\
\hline
\end{tabular}

Fonte: Organizado pelos autores (2020).

Nos Quadros 03 e 04, opondo-se aos achados anteriores, das 44 teses e dissertações, entre 2015 e 2019, foram publicadas apenas 16, distribuídas igualmente, indicando redução do interesse investigativo por essa temática. Possivelmente, por terem projetos elaborados anteriores à 2015, ou próximo a esse período, o debate levantado a partir da Resolução n ${ }^{\circ}$ 02/2015-CP/CNE não tenha repercutido nos objetos de investigação. Observou-se que o termo 'concepção' também teve prevalência em relação ao termo 'conceito' de docência, igualando-se aos artigos analisados.

Assim, o corpus de análise envolveu 23 produções acadêmicas, sendo 07 artigos e 16 dissertações/teses, todas publicadas entre os anos de 2015 e 2019, disponibilizadas no portal Periódicos Capes e na BDTD, respectivamente. Feita a descrição da etapa inicial do Estado Questão, apresenta-se a seguir o exame dos documentos identificados, situando percepções e situando percepções, explicitando a ênfase dada nas produções selecionadas e relacionando-as às definições acerca da docência e do seu conceito.

\section{A acepção de docência: compreensões nas produções acadêmicas.}

Considerando o número de produções que se utilizaram dos termos concepção ou conceito de docência (Quadros 01 e 03), o que manifesta maior adesão nas pesquisas é o primeiro. Essa sinonímia suscita reflexão de caráter etimológico, encontrando suporte no Dicionário de Filosofia (ABBAGNANO, 1998), o qual refere-se ao termo conceito como "generalíssimo", cuja definição aplica-se à "Processo que torne possível a descrição, a classificação e a previsão dos objetos cognoscíveis" (p. 164) e trata-se de "um signo do objeto (qualquer que seja) e se acha em relação de significação com ele" (p. 166). Adicionalmente, de acordo com a mesma fonte (p. 169), concepção está se relacionado "tanto o ato do conceber quanto o objeto concebido, mas, preferivelmente, o ato de conceber e não o objeto, para o qual deve ser reservado o termo conceito", o que leva crer a melhor aplicação do termo conceito, pelo interesse na significação, na representação do objeto, no caso, a docência.

Os 07 artigos selecionados versam sobre a formação de professoras(es), sendo 04 deles relacionadas à docência no ensino superior em áreas cuja discussão sobre a dicotomia entre a formação didático-pedagógica e os conhecimentos disciplinares (específicos) é marcante. Registra-se estudos sobre a formações de professoras(es) dos cursos da área da Saúde, de graduação tecnológica de Design de Moda, do Direito e da Educação Profissional e Tecnológica. Os outros 03 delimitam suas investigações na formação inicial, sendo 02 envolvendo as licenciaturas das Ciências da Natureza e 
Matemática e, provavelmente, por abrangerem áreas do específicas do conhecimento, definir o conceito de docência tenham encontrado razão para centralizarem tal temática nas fundamentações das publicações analisadas. Destaca-se, ainda entre os que se ativeram às licenciaturas (03), a prevalência de análises de experiências no âmbito do Pibid como espaço de formação (02).

As dissertações (08) e as teses (08), em sua maioria (14), foram desenvolvidas em programas/cursos da Educação e apenas 02 em outras áreas: uma tese em um programa de Química e outra de Enfermagem Psiquiátrica, ambas detiveram olhares sobre o conceito de docência. Imersos no grande contexto interdisciplinar da Educação, registrou-se investigação sobre o ensino nas áreas de Ciências Humanas (02 - história e filosofia), de Linguagens/Artes (02), de Ciências da Natureza e Matemática (04), na EJA (01), na área médica (01), na Educação Infantil (01), no Ensino Técnico Magistério (01) e tratando da percepção do conceito de docência em professoras(es) em geral (04). Quanto à etapa de formação ou atuação, 03 destinaram-se para licenciandos, 07 para formação de professoras(es) da Educação Básica e 06 com docentes da Educação Superior. Como ocorreu nos artigos, porém com menor recorrência, apenas 02 teses e 01 dissertação envolveram sujeitos participantes do Pibid, buscaram compreender a constituição da docência e práticas desenvolvidas como superação à uma docência dita tradicional.

Examinando os artigos, dissertações e teses identificadas para esse EQ, evidenciou-se que o conceito de docência ainda está pouco problematizado, dado o diminuto número de produções acadêmicas que o abordam, fazendo parecer que há uma definição tácita no campo de investigação. As publicações tratam do trabalho docente, sem, contudo, delimitar o que seja essa atuação profissional, levando a uma consideração pela aproximação do modus operandi profissional, imiscuindo-se o conceito com o de prática docente. Os autores desses estudos chegam à compreensão observando a percepção de quem atua na profissão, sem indicar qual a compreensão utilizada na investigação, levando a certa confusão ou senso comum na definição do que seja o conceito de docência.

Nos artigos, chega-se ao conceito de docência por aproximação, ao identificar o que reclamam para a superação de uma racionalidade técnica, uma mera "transmissão" ou "domínio" de conteúdos (VOLKMAN; PEREIRA; LUCCAS, 2019; COLLARES; OLIVEIRA, 2018; PAEZ; PEREIRA, 2017; MASSENA; CUNHA, 2016). Nas teses e dissertações essa indefinição o fato se agrava por algumas delas apresentarem como um dos seus objetivos buscar a compreensão dos sujeitos acerca da docência, intenção manifesta sem uma definição explícita das conceituações do referencial que baliza o estudo (COSTA, 2015; SILVA, 2018; RIBEIRO, 2019), reforçando a ideia que partem da existência de uma definição tácita no campo, sobre o conceito que se propunham definir ou investigar. Percebe-se, grosso modo, que a docência envolve dimensões que 
vão além do "dar aula" e elas (as aulas) são mais que momentos de repasse de conteúdos previamente sistematizados.

Alguns dos documentos analisados trazem suas formulações sobre o conceito de docência ligados à alguma especificidade, seja conceitual ou ligada à delimitação de sua atuação, o que gerou alguma particularidade, sistematizados no Quadro 05.

Quadro 05 - Formulações sobre o conceito de docência nos artigos, teses e dissertações identificados no Periódicos Capes e no BDTD, no período de 2015 a 2019.

\begin{tabular}{|c|c|c|}
\hline Conceito/Ideia & Síntese & Autor/ano \\
\hline Docente Artista & $\begin{array}{l}\text { Olhar a docência esteticamente, como uma 'obra de } \\
\text { arte' é, de alguma forma, assumir que a cena docente } \\
\text { é feita de dificuldades, dissonâncias, resistências, } \\
\text { frustrações, erros, acertos, mudanças de rumo, } \\
\text { dúvidas, incertezas, conquistas, sucessos. E aí a } \\
\text { docência pode sim aprender muito com os artistas, } \\
\text { parafraseando o filósofo Nietszche. Nesse processo, } \\
\text { acredito na importância da escrita de si docente } \\
\text { (textos, cartas, memoriais, portfólios) e das relações } \\
\text { de amizade (grupos de formação docente, relações } \\
\text { intersubjetivas), modos estéticos de colocar-se em } \\
\text { cena para si mesmo (LOPONTE, 2015, in } \\
\text { MANZONI, 2018, p. 76). }\end{array}$ & $\begin{array}{l}\text { Storck, } 2015 \\
\text { Selbach, } 2016 \\
\text { Manzoni, } 2018 \\
\text { Silva, } 2018\end{array}$ \\
\hline $\begin{array}{l}\text { Docência } \\
\text { Universitária }\end{array}$ & $\begin{array}{l}\text { [...] conceito de docência superior/universitária estão } \\
\text { imbricadas, conforme Cunha e Isaia (2003, p. 372), } \\
\text { "atividades desenvolvidas pelos professores para a } \\
\text { preparação de futuros profissionais, baseadas não } \\
\text { somente em conhecimentos, saberes e fazeres, mas } \\
\text { também nas relações pessoais e afetivas". Assim, a } \\
\text { docência é um amálgama da dimensão técnica com a } \\
\text { pessoal. Ou seja, o professor exerce uma tarefa } \\
\text { complexa em que estão implicadas as dimensões } \\
\text { cognitivas, culturais e subjetivas (MASSENA; } \\
\text { CUNHA, 2016, p. 204). }\end{array}$ & $\begin{array}{l}\text { Massena e Cunha, } \\
2016 \\
\text { Paz e Pereira, } 2017 \\
\text { Sandri, } 2017 \\
\text { Santos, } 2017 \\
\text { Oliveira, } 2018 \\
\text { Collares } \\
\text { Oliveira, } 2018 \\
\text { Oliveira, 2018 } \\
\text { Volkman, Pereira e } \\
\text { Luccas, 2019 }\end{array}$ \\
\hline $\begin{array}{l}\text { Docente } \\
\text { Intelectual }\end{array}$ & $\begin{array}{l}{[\ldots] \text { o docente intelectual comprometido com a }} \\
\text { (re)construção dos significados epistemológicos } \\
\text { legitimados entre o conhecido e ao conhecer, ou } \\
\text { ainda, entre o ensinado e ao ensinar. O sentido } \\
\text { pedagógico na busca de superação de dicotomias } \\
\text { liberais burguesas, além de estabelecer-se uma } \\
\text { relação de subordinação vinculada de forma tensa à } \\
\text { suporta autonomia intelectual discente, apenas } \\
\text { imitando que socialmente reconhecido. (ALMEIDA, } \\
\text { 2015, p. 101) }\end{array}$ & Almeida, 2015 \\
\hline $\begin{array}{l}\text { Docência em } \\
\text { Movimento }\end{array}$ & $\begin{array}{l}\text { [...]quando o professor reflete criticamente sobre sua } \\
\text { prática, ele evoca as teorias pedagógicas e os saberes } \\
\text { que possui, a fim de pensar uma nova ação, } \\
\text { movimentando constantemente seu fazer docente (p. } \\
\text { 26). }\end{array}$ & $\begin{array}{l}\text { Selbach, } 2016 \\
\text { Roncarelli, } 2019\end{array}$ \\
\hline
\end{tabular}




\begin{tabular}{|l|l|l|}
\hline & {$[\ldots]$ reflexão sobre a prática o coloca em ação- } \\
reflexão-ação: isso caracteriza a docência em \\
movimento, sempre permeada pelos contextos de \\
vida, históricos, políticos e locais que compõem a \\
educação. Dessa forma, é possível afirmar que, para \\
que a docência em movimento se evidencie, a reflexão \\
sobre a prática é imprescindível. (RONCARELI, \\
2019, p. 31)
\end{tabular} \mid

Fonte: Organizado pelos autores (2020).

A análise das produções identificadas no Quadro 5 demonstra a prevalência da problematização sobre o conceito de docência, seja definido de forma ampla ou destacando algumas de suas particularidades, essencialmente, no magistério do Ensino Superior. Docente artista foi outro elemento presente nesse contexto de definições das características mencionadas, muito relacionada à dimensão estética e à formação/atuação em cursos/disciplinas da área de Artes. As demais, demonstraram-se ser, possivelmente, formulações próprias com destaque à algum aspecto presente em outras considerações sobre a docência, como a reflexividade, intelectualidade, profissionalidade $\mathrm{e}$ institucionalidade.

O conceito de docência nas demais produções ora chama para superação de uma visão simplista (tecnicista) da prática profissional, ora reclama para a ampliação das dimensões que basilam suas concepções, com certo destaque à estética, dada as investigações que dispensam olhares para docência nas Artes, sobretudo. Converge, nos achados, a necessidade de imbricação entre formação e atuação, entre teoria e prática, entre o 'ensinante e o ensinado', portanto, uma prática relacional e processual, em transformação. Para além desta movimentação, reconhecem também o papel da docência na transformação da sociedade, na reflexão sobre os contextos de atuação de forma crítica, aludindo a ela o traço de prática social.

A dimensão política é escamoteada das conceituações, relegada a uma dimensão subliminar, quase alheia à formação de professoras(es). Tal fato é revelador de uma rarefeita compreensão da relevância da consciência política às(aos) docentes e uma vez desconhecida ou relativizada - quando muito, o(a) educador(a)não atentará que sua atuação se dá em contexto "tensão política permanente" e que seu trabalho deve - ou pelo menos deveria buscar "conjugar uma prática pedagógica eficiente a uma ação política da 
mesma qualidade", para o alcance de uma prática transformadora (FERNANDES, 1983, p. 31).

Nesse sentido, buscando encontrar convergência e aproximar-se de uma conceituação, destaca-se definição que agrega esses elementos, elaborada por Santos (2017) para fundamentar sua tese, e na qual explicita que sua compreensão sobre a docência:

[...] é entendê-la como constituída e constituinte no plano das determinações e relações sociais, é considerar o espaço educativo como um espaço de construção do conhecimento. Sendo o conhecimento pensado como uma construção histórica, contextualizado e elaborado por homens e mulheres com implicações políticas, sociais, econômicas e éticas. Sem desconsiderar, ainda, as questões subjetivas de professores e alunos, as quais estão implícitas emoções, criatividade, intuição e valores que estão envolvidos neste processo. Isso requer diálogo, negociação e reflexão crítica permeada por atitude ética. Desta forma professores e alunos são vistos como sujeitos da práxis que aprendem, ensinam e transformam, ou seja, realizam a ação. Sendo que a dimensão coletiva é fundamental ao longo de todo processo. Assim a educação só possui sentido na medida em que as estruturas, processos e relações nas quais ela se efetiva explicitam os limites da alienação humana e, potencialmente, a humanização do indivíduo (SANTOS, 2017, p. 101).

De modo pontual entre os documentos analisados, na formulação de Santos (2017) é nítido o imbricamento político a que o conceito de docência remete, entendimento que fortalece o objeto de estudo acerca da percepção, do investimento e da incorporação do seu papel como sujeito político - a consciência ampliada de docência. Esta conjugação, aliada a dimensão estética e ética da docência, presente na Resolução $\mathrm{n}^{\mathrm{o}}$ 02/2015-CNE/CP, influenciou a compreensão do conceito, seja pela sua amplitude ou pelo discurso oficial do documento, fato, possivelmente, decorrente da importância na política de formação de professoras(es) até o final de 2019, quando houve a publicação de nova diretriz ${ }^{6}$ que sinaliza para outro rumo, não necessariamente implicando avanço, mas um grave retrocesso.

O artigo de Silva (2016) e três produções decorrentes de estudos stricto sensu (BEZERRA, 2016; SABBAG, 2017; DI NAPOLI, 2019) fazem referência ao conceito de docência registrado no documento do Conselho Nacional de Educação publicado em 2015. Convém destacar que o CNE se embasa no construto histórico da Associação

\footnotetext{
${ }^{6}$ Em 20 de dezembro de 2019 foi publicada nova Diretriz Curricular para a formação de professoras(es) da educação básica $\left(\mathrm{DCN} \mathrm{n}^{\circ} 02 / 2019\right.$ - $\left.\mathrm{CNE} / \mathrm{CP}\right)$, que, entre muitos retrocessos, não faz considerações sobre o que considera ser a docência. Por aproximação sobre a concepção de formação, compreende-se que a docência é aquela circunscrita às habilidades e competências prescritas na BNCC e na Base da Formação de Professores, uma novidade que impõem às licenciaturas padronização curricular.
} 
Nacional pela Formação dos Profissionais da Educação (ANFOPE), por meio do Movimento dos Educadores, desde o início da década de 1980.

A dissertação de Bezerra (2017), cujo objeto gira em torno da análise sobre as diretrizes curriculares nacionais para formação de professoras(es) de 2002 a 2015, traz elementos do que define ser uma docência "alargada", ao analisar o perfil da(o) pedagoga(o) nas DCN n ${ }^{0}$ 01/2006. A autora faz crítica sobre essa expansão estar, de algum modo, relacionada ao atendimento dos interesses neoliberais, que possibilitam responsabilização e degradação das(os) docentes. Em suas palavras:

[...] contatou-se que o perfil do pedagogo apresentado assume uma concepção de docência alargada e atende às demandas da sociedade capitalista ao tomar com princípios norteados a adaptabilidade, a polivalência e a flexibilidade (BEZERRA, 2017, p. 151).

[...] Esse "alargamento" das funções pode ser interpretado como uma possibilidade de ampliação na autonomia docente, pois a assunção dessas novas responsabilidade implica de forma mais direta o professor "como pessoa e como profissional" (NÓVOA, 1992). Todavia, é preciso considerar que, se por um lado esse "alargamento" traz possibilidade de maior autonomia e de controle sobre as atividades docentes, por outro, produz também intensificação do trabalho contribuindo para degradação das condições em que atuam milhares de professores [...] (BEZERRA, 2017, p. 138).

Por outro lado, a mesma autora reconhece nas DCN no 02/2015 um redimensionamento na pauta formativa de professoras(es), concebendo a docência integrada a processo articulados "de ensino e aprendizagem e na organização e gestão da Educação Básica”, em um processo orgânico entre espaço formativo e de atuação profissional, representando conquista histórica no campo da formação de professoras(es).Registra-se que a pesquisadora não faz destaque à dimensão política da formação de professoras(es) nas suas constatações sobre ampliação do conceito de docência. Essa ausência também se verifica nas análises de Di Napoli (2019), quem também examina as Diretrizes de 2015 para formação de professores.

De certo que a docência é uma atividade profissional que envolve diversidade de dimensões, de contextos, de exigências formativas, de espaços de atuação, de particularidades e ao fazerem conceituações sob um desses aspectos não se observa sua totalidade, chega-se a ela apenas por "diferentes acessos e ingressos", o que "pode conduzir a unilateralismos, no sentido de fazer sobrepujar um dado enfoque sobre outro" (VEIGA; ARAÚJO; KAPUZINIAK, 2005, p. 15). Nas produções examinadas, de maneira genérica, houve uma percepção reducionista do conceito de docência, delimitada ao seu fazer, à sua dimensão operacional. Não houve uma análise “omnilateral”. 
As considerações feitas acerca das 23 produções acadêmicas - artigos, dissertações e teses - propiciaram elucidar como o conceito de docência foi problematizado nesses estudos, produzidos no interregno de 2015 a 2019. As evidências advindas dessas leituras, e detalhadas até aqui, por certo aportaram subsídios relevantes para a delimitação da temática, objeto dessa análise, como anotado nas considerações que seguem, as quais fecham esse escrito.

\section{Considerações finais: contribuições do EQ para a compreensão do conceito de docência}

Não incomum, a formação de professoras(es) pouco oportuniza discussão política que possibilite "recuperar e preservar elementos de identidade cultural, que alimentem e potencializem o processo de tomada de consciência crítica", anotam Giareta e Meneghel (2008, p. 06). A asserção dos autores brasileiros chama atenção para o tangenciamento ou ausência nos projetos pedagógicos dos cursos e, por conseguinte, da formação docente, da dimensão política, a despeito dos preceitos legais que a indicavam como constitutiva da docência. É grave essa deficiência, sobretudo pelo momento em que se busca uma normalização de professoras(es) no Brasil, considerando o esvaziamento de conteúdos e limitação da formação inicial a uma base que prescreve os currículos na Educação Básica. A consequência disso fará com que professoras(se) se distanciem sobre o agir nos tensionamentos que cercam sua prática e a vida dos seus estudantes, sejam em questões culturais, ambientais, ou com implicâncias sociais, quiçá até mesmo de questões relacionadas ao ensino e a aprendizagem.

Estas ponderações preliminares visam realçar o quão necessário é a dimensão política para a formação de professores, sejam iniciantes ou experientes, sem, é obvio, desconsiderar que a docência é constituída de múltiplas abordagens, conjunturas e perspectivas. Observou-se reflexo desse silenciamento nas análises dos textos acadêmicos em nível stricto sensu e em artigos publicados em periódicos que compuseram a aproximação inicial à temática, envidada por meio do EQ.

Os estudos analisados, grosso modo, relacionam a docência à ato intencional, subjetivo e complexo. Consideram-na como uma atividade imprevisível e abrangente, dada suas possibilidades de atuação e sua condição relacional. Apontam que a docência requer formação específica, pautada numa racionalidade prático-reflexiva e críticoemancipatória, e que reclama desenvolvimento profissional contínuo, como parte da profissionalização docente. Salta aos olhos o fato de apenas dois trabalhos tecerem alguma referência à dimensão política na explicitação do conceito de docência, elemento que, na percepção dos autores desse texto, é essencial a conceituação ampliada da docência. 
Aliás, esse é um indicativo evidenciado a partir da realização do exercício analítico possibilitado pelo EQ: o conceito de docência ampliada encontra na dimensão política da atuação profisssional um elemento fundante. É essa dimensão e, principalmente, seu exercício, que instiga e impulsiona a consciência do sujeito profissional que concretiza esse trabalho, com implicações sobre "o pensar e o fazer político e pedagógico do professor para além do ensino", tal como formulado por Dourado (2017, In: VILLAS BOAS, 2018, p. 85). Esse alargamento do referencial do agir docente, para além dos limites circunscritos ao ensinar, refere-se "[...] às ideias, aos valores e às atitudes dos professores, assim como aos alertas de professores e investigadores sobre a realidade educativa" (ALARCÃO, 2020, p. 70), revela o movimento de assunção da dimensão política nos modos de compreender e de atuar como docente. Corrobora-se o argumento da autora portuguesa de que a dimensão política é transversal e enquadradora de prática docente e é nessa perspectiva que se alude a ampliações do conceito de docência.

As análises indicam que o conceito de docência teve tímido visibilidade no período analisado (2015-2019), dado o reduzido volume de produções acadêmicas identificadas a partir dos descritores utilizados. Essa constatação dá indicação de três possibilidades: i) necessidade de outros refinamentos na definição do corpus de análise ou a ampliação dos descritores e bases de consulta; ii) trata-se de um tema estabelecido e nesta situação requer-se ampliação do recorte temporal para melhor conhecimento da questão ou; iii) há percepção tácita no campo sobre a docência, possivelmente, não despertando interesse por novas investigações acerca da questão.

Os estudos trazem formulações com denominações diversas que ligam a docência à movimento, à artística, à intelectualidade, à crítica ou ao contexto profissional em que o professor atua, seja no ensino superior, no ensino de ciências, de filosofia, de direito, de história e da área de saúde, no ensino online. As produções acadêmicas analisadas, ao traçarem uma definição, relacionam a docência a características como da complexidade, da reflexividade, da subjetividade e, dada sua peculiaridade relacional, como capaz de promover transformação social. Essas foram as congruências observadas em relação ao conceito de docência nos artigos, teses e dissertações.

Estas evidências da leitura, viabilizadas por meio da busca e análise realizada, ao desvelar a componente da consciência como importante para a compreensão do conceito de docência numa perspectiva ampliada, explicita esse construto como objeto prenhe de possibilidades para a compreensão da formação e do desenvolvimento profissional docente. 


\section{Referências}

ALARCÃO, I. Percursos da Didática. $1^{\text {a }}$ Ed. Coleção Educação e Formação - Cadernos Didáticos, número 4. Aveiro: UA Editora. 2020.

ALMEIDA, V. T, de. O ensino da filosofia nas diretrizes de Jean Maugüé e no historicismo do pensamento de João da Cruz Costa: pioneirismo na Universidade de São Paulo. 2015. 128 f. Dissertação (Mestrado) - Mestrado em Educação FHD UMSP, São Bernardo do Campo, 2015.

BATTISTI, A.; MARTINS, L. Formação docente no Brasil: Cenários e desafios. InterCambios, Montevidéu, v. 3, nº 2, 2016.

BELL, J. Projeto de Pesquisa: Guia para pesquisadores iniciantes em Educação, Saúde e Ciências Sociais. Tradução Magda França Lopes. $4^{\mathrm{a}}$ edição. Porto Alegre: Artmed, 2008.

BEZERRA, A. M. C. A Formação de professores no Brasil: Um estudo das diretrizes curriculares nacionais para a formação inicial e continuada dos professores (2002-2015). 2017. 177 f. Dissertação (Mestrado) - PPGE UFPB, João Pessoa, 2017.

BRODBECK, C. F. Docência em ciências nas práticas pibidianas do subprojeto biologia e a fabricação de uma pedagogia da redenção. 2015. 166 f. Tese (Doutorado) - PPGE UNISINOS, São Paulo, 2015.

BRASIL. Conselho Nacional de Educação. Conselho Pleno Resolução $N^{o}$ 2, de 1 de julho de 2015. Define as Diretrizes Curriculares Nacionais para a formação inicial em nível superior (cursos de licenciatura, cursos de formação pedagógica para graduados e cursos de segunda licenciatura) e para a formação continuada. Brasília, 01/07/2015. Disponível em http://portal.mec.gov.br/docman/agosto-2017-pdf/70431-res-cne-cp-002-03072015pdf/file Acesso em 21/12/19.

CARDOSO, N. S.; MENDONÇA, S. G. L. A trajetória de atuação do Forpibid-RP: entre inovar a formação e resistir aos ataques. Formação em Movimento. v.1, n.1, p.146-152, jan./jun. 2019.

COLARES, K. T. P.; OLIVEIRA, W. Metodologias Ativas na formação profissional em saúde: uma revisão. Revista SUSTINERE, Rio de Janeiro, v. 6, n. 2, p. 300-320, jul-dez, 2018.

CORRÊA, C. P. Q. A formação dos formadores do programa institucional de Bolsa de Iniciação à Docência (PIBID). 2017. 245 f. Tese (Doutorado) - PPGE UFJF, Juiz de Fora, 2017.

COSTA, M. R. G. Docência e história de vida no curso técnico em magistério de Catalão - GO. 2015. 79 f. Dissertação (Mestrado) - PPGE UFG, Goiânia, 2015.

CRESWELL, J. W. Projeto de Pesquisa: Métodos qualitativo, quantitativo e misto. Tradução Luciana de Oliveira Rocha. $2^{\mathrm{a}}$ edição. Porto Alegre: Artmed, 2007. 
DI NÁPOLI, B. L. S. (2019). A formação inicial de professores e a educação de jovens e adultos. 2019. 105 f. Tese (Doutorado) - PPGE UFG, 2019.

DOURADO, L. F. Entrevista in: VILLAS BÔAS, F. L. Um Estudo Avaliativo do Pibid: Contribuições para Avaliação de Programas Educacionais. 2018. 179 f. Tese (Doutorado) - PPGDSCI, UnB, Brasília, 2018.

GIARETA, P. F.; MENEGHEL, S. M. A Dimensão Política na Prática Pedagógica da Formação de Professores do Ensino Superior. Anais. I Congresso Nacional de Educação EDUCERE. Curitiba: PUCPR, 2008. Disponível em: http://educere.bruc.com.br/ arquivo/pdf2008/763 653.pdf. Acesso em 27 ago. 2018.

JOSSO, C. Experiências de vida e formação. 285p. São Paulo: Cortez. 2004.

MANZONI, D. M. Dançografia em processo de criação: Uma docência artista em dança. 2018. 158 f. Tese (Doutorado) - PPGE UFSM, Santa Maria, 2018.

MASSENA, E. P.; CUNHA, M. I. O potencial formativo do Pibid pela perspectiva dos formadores de professores. RBPG, Brasília, v. 13, n. 30, p. 195 - 220, jan./abr. 2016.

MENDES, E. T. B.; FARIAS, I. M. S.; NÓBREGA-THERRIEN, S. M. Trabalhando com materiais diversos e exercitando o domínio da leitura: a pesquisa bibliográfica e a pesquisa documental. In: NÓBREGA-THERRIEN, S. M.; FARIAS, I. M. S.; NUNES, J. C. (Orgs.) Pesquisa cientifica para iniciantes: caminhos no labirinto. Fortaleza: EdUECE, 2011, p.25-42 (vol. III).

NÓBREGA-THERRIEN, S. M.; THERRIEN, J. Trabalhos Científicos e o Estado da Questão: reflexões teórico-metodológicas. Estudos em Avaliação Educacional, São Paulo, v. 15, n. 30, jul-dez/2004.

O estado da questão: aportes teórico-metodológicos e relatos de sua produção em trabalhos científicos. In: FARIAS, I de; NUNES, J. C.; NÓBREGA-THERRIEN, S. M. (Orgs.) Pesquisa cientifica para iniciantes: caminhos no labirinto. Fortaleza: EdUECE, 2011, p.33-51 (vol. I).

OLIVEIRA, R. G. Docência Universitária na Saúde: limites e possibilidades para uma prática inovadora. 2018. 107 p. Tese (Doutorado) - EE USP, Ribeirão Preto, 2018.

PAEZ. F. M.; PEREIRA, A. S. Formação continuada: a visão dos professores de um curso de graduação tecnológica. Acta Scientiarum. Education, Maringá, v. 39, suppl., p. 567$575,2017$.

PRADO, E. C.; SANTOS, C. M.; PEREIRA JÚNIOR, A. M. Pós-graduação stricto sensu em Direito: onde e como se forma o docente dos cursos de graduação. $R B P G$, Brasília, v. 12 , n. 28, p. $443-470$, agosto de 2015.

RIBEIRO, M. F. d. B. S. Formação pedagógica nos programas de pós-graduação stricto sensu da Unioeste /campus Cascavel-PR: Um estudo sobre o estágio de docência. 2019. 109 f. Dissertação (Mestrado) - PPGE UNIOESTE, Cascavel, 2019. 
RONCARELLI, I. A. Docência em movimento, entrecruzamentos de percursos de vida e percursos docentes: O que acontece com as professoras? 2019. 155 f. Dissertação (Mestrado) - PPGE UCS, Caxias do Sul, 2019.

SABBAG, S. (2017). "Porque a gente tem um corpo né... mas a gente só lembra do corpo quando ele dói": A centralidade do corpo adulto nas relações educativas na educação infantil. 2017. 248 f. Tese (Doutorado) - PPGE UFSC, Florianópolis, 2017.

SANDRI, V. Aprendizagem docente no ensino superior: Processos formativos de professores e estudantes nas licenciaturas da área de ciências biológicas, exatas e da terra. 2017. 314 f. Tese (Doutorado) - PPGE UFSM, Santa Maria, 2017.

SANTOS, J. D. A. Aspectos relevantes das políticas públicas de formação de professores: Considerações dos gestores educacionais da cidade de Goiânia. 2017. 253 f. Tese (Doutorado) - PPGQ UFG, Goiânia, 2017.

SELBACH, S. A constituição da docência em blogs do PIBID: Um estudo sobre os modos de escrita de si. 2016. 112 f. Dissertação (Mestrado) - PPGE UCS, Caxias do Sul, 2016.

SILVA, F. L. Carência de professores licenciados em Matemática em Corrente: Um estudo a partir das representações sociais. 2018. 297 f. Tese (Doutorado) - PPGE UFMG, Belo Horizonte, 2018.

SILVA, F. L. G. R. Plano Nacional de Educação e seus desdobramentos sobre as novas diretrizes para a formação de professores da educação profissional: identidades profissionais em construção. HOLOS, Ano 32, Vol. 6, p. 156-177, 2016.

STAKE, R. E. Pesquisa Qualitativa: estudando como as coisas funcionam. Porto Alegre: Penso, 2011.

STORCK, K. Como viver na escola: Relações entre arte, educação e docência. 2015. 153 f. Dissertação (Mestrado) - PPGE UFRS, Porto Alegre, 2015.

VEIGA, I. P. A.; ARAÚJO, J. C. S.; KAPUZINIAK, C. Docência: uma construção éticoprofissional. 142 p. Campinas: Papirus, 2005.

VILLAS BÔAS, F. L. Um Estudo Avaliativo do Pibid: Contribuições para Avaliação de Programas Educacionais. Tese (Doutorado) - Programas de Pós-Graduação em Desenvolvimento Sociedade e Cooperação Internacional. Universidade de Brasília: 28 de mar. de 2018.

VOLKMAN, E.; PEREIRA, A. L.; LUCCAS, S. Aprendendo a ensinar na formação inicial de professores de matemática: uma análise das concepções discentes. Educ. Matem. Pesq., São Paulo, v.21, n.2, pp. 353-378, 2019. 
*Nilson de Souza Cardoso Professor Assistente Universidade Estadual do Ceará (Uece) no curso de Licenciatura em Ciências Biológicas (Campus Crateús) e no Mestrado Profissional em Ensino de Biologia em Rede Nacional (Profbio). É pesquisador e membro do grupo de pesquisa Educação, Cultura Escolar e Sociedade (EDUCAS) e doutorando no PPGE/Uece. Presidente do Fórum de Coordenadores Institucionais do Pibid e Residência Pedagógica (FORPIBID-RP).

E-mail: nilson.cardoso@uece.br

https://orcid.org/0000-0003-3214-8942

**Isabel Maria Sabino de Farias Professora Associada da Universidade Estadual do Ceará (Uece), vinculada ao Programa de Pós-Graduação em Educação (PPGE)/ Centro de Educação (Ced). Líder do grupo de pesquisa Educação, Cultura Escolar e Sociedade (Educas), realizando estudos sobre desenvolvimento profissional docente, inovação e docência.

E-mail: isabelinhasabino@yahoo.com.br

https://orcid.org/0000-0003-1799-0963 